\title{
DIFFUSE IDIOPATHIC SKELETAL HYPEROSTOSIS (DISH) OF THE ELBOW: A CAUSE OF ELBOW PAIN? A CONTROLLED STUDY
}

\author{
By CH. BEYELER, ${ }^{*}$ P. SCHLAPBACH, ${ }^{*}$ N. J. GERBER, ${ }^{*}$ H. FAHRER, ${ }^{*}$ F. HASLER, ${ }^{*}$ \\ S. M. VAN DER LINDEN, ${ }^{*}$ U. BÜRGI, $\dagger$ W. A. FUCHS $\ddagger$ AND H. EHRENGRUBER \\ Departments of ${ }^{*}$ Rheumatology, tInternal Medicine, $\ddagger$ Radiology and $§$ Data Processing, University of \\ Berne, Inselspital, CH-3010 Berne, Switzerland
}

\begin{abstract}
SUMMARY
Elbow pain is a common complaint and elbow hyperostosis a frequent radiological condition. However, little is known about the association between the clinical and radiological findings. To evaluate the relationship between spinal and extraspinal hyperostotic features and the clinical relevance of elbow hyperostosis we have performed the first controlled, double-blinded study of 85 hospitalized probands, 33 with and 52 without thoracospinal hyperostosis on lateral chest $\mathrm{X}$-ray. Elbow and shoulder hyperostosis were graded on bilateral standard radiographs. Elbow pain was assessed by an interviewer using a standardized questionnaire and extraskeletal causes of elbow pain were recorded. The prevalence of elbow hyperostosis was increased in cases with thoracospinal hyperostosis compared to controls $(82 \%$ versus $58 \%$, $\chi^{2}=5.32, P<0.025, n=85$, odds ratio (OR) 3.30 (95\% CI 1.16-9.35)). Similarly, the prevalence of elbow hyperostosis was increased in cases with shoulder hyperostosis compared to controls $\left(83 \%\right.$ versus $60 \%, \chi^{2}=4.51, P<0.05, n=84$, $\mathrm{OR}=3.20(95 \%$ CI 1.06-9.66)), emphasizing the multifocal nature of hyperostotic features. Elbow pain was only slightly more prevalent in cases with elbow hyperostosis compared to controls $\left(21 \%\right.$ versus $13 \%, \chi^{2}=0.75, \mathrm{NS}, \mathrm{OR}=1.84(95 \%$ CI $0.46-7.44)$ ). We conclude that elbow hyperostosis is a radiological finding of doubtful clinical relevance.
\end{abstract}

KeY words: Hyperostosis, Spinal osteophytosis, Elbow, Pain.

DiffuSE idiopathic skeletal hyperostosis (DISH) is a frequent condition with both spinal and extraspinal findings [1-3]. It is characterized by anterolateral spinal ligamentous calcification or ossification [1-7] and extraspinal ossification at entheses with formation of bony spurs [1-3, 8-14]. Sites commonly involved are the shoulder, elbow, hand, pelvis, hip, knee and heel.

Although hyperostotic changes at the elbow have been described previously [1-3,9-13], no criteria for radiological grading have been published. In addition, the clinical relevance of the peripheral radiological findings has not yet been defined, despite the fact that several open, uncontrolled studies reported complaints at sites of joint involvement, including the elbow $[1,2,8-10,14]$.

We therefore performed the first controlled study with the following aims:

(1) to develop radiological criteria for the grading of elbow hyperostosis;

(2) to evaluate a possible association between thoracospinal hyperostosis and elbow hyperostosis;

(3) to analyze a possible relationship between shoulder hyperostosis and elbow hyperostosis;

(4) to assess the clinical relevance of elbow hyperostosis as a cause of elbow pain.

\section{MATERIALS AND METHODS}

A controlled study was performed on patients hospitalized for reasons other than skeletal pain. Consecutive routine lateral chest $\mathrm{X}$-rays performed on admission to two departments of internal medicine and

Submitted 29 January; revised version accepted 18 June 1991

Correspondence to $\mathrm{Dr} \mathrm{Ch}$. Beyeler, Department of Rheumatology, University of Berne, Inselspital, CH-3010 Berne, Switzerland. one of cardiovascular surgery were screened for thoracospinal hyperostosis. Two hundred and eighty-four probands, 106 with and 178 without hyperostotic features, were recruited, deliberately excluding probands suffering from obvious oncological, rheumatological, orthopaedic or neurological diseases. Eighty-five of the above 284 gave consent to a complete radiological examination of both elbows and are the focus of this study.

Clinical symptoms such as elbow pain during the last 6 months or before, history of work and cause of hospital admission were collected by one of two independent, blinded interviewers ( $\mathrm{CHB}, \mathrm{EH})$, using a standardized questionnaire. Occupational activities were classified as physically 'heavy' or 'light' by consensus of the two interviewers. Extra skeletal causes of elbow pain were recorded by a blinded physician (UB) on the basis of the medical records.

Lateral chest $\mathrm{X}$-rays were graded blindly by a rheumatologist (PS) as follows [7]:

$$
\begin{aligned}
\text { Thoracospinal hyperostosis DISH-grading } \\
\begin{aligned}
& \text { Grade } 0= \text { no ossification. } \\
& \text { Grade I }= \text { prevertebral and/or prediscal ossi- } \\
& \text { fication at } 1 \text { or } 2 \text { vertebral bodies of } \\
& \text { the spine or a single bridging ossifi- } \\
& \text { cation between vertebrae. } \\
& \text { Grade II }= \text { continuous flowing prediscal } \\
& \text { and/or prevertebral ossification } \\
& \text { along three or more vertebral } \\
& \text { bodies, or two bridging ossifica- } \\
& \text { tions. } \text { three or more bridging prediscal or } \\
& \text { prevertebral ossifications. }
\end{aligned}
\end{aligned}
$$

The intervertebral discs of the hyperostotic seg- 
ments were not allowed to show any degenerative, inflammatory or dysplastic abnormalities [7]. Grades 0 to I were considered as 'thoracospinal hyperostosis absent' (= controls), grades II and III as 'thoracospinal hyperostosis present' (cases).

Bilateral elbow X-rays with anterioposterior and lateral views were performed, graded blindly and independently by a rheumatologist (NJG) and a radiologist (WAF).

$$
\begin{aligned}
& \text { Elbow hyperostosis grading comprised: } \\
& \text { Grade } 0=\text { none or only one ossification }
\end{aligned}
$$

Grades 0 and I were classified as 'elbow hyperostosis absent' (= controls), grades II and III as 'elbow hyperostosis present' (cases). In addition, the presence of other skeletal changes such as chondrocalcinosis, inflammatory or degenerative features, and amorphous soft tissue calcifications were noted.

Eighty-four out of the 85 probands also agreed to bilateral shoulder $\mathrm{X}$-rays in three directions, graded blind and independently by a rheumatologist (NJG) and a radiologist (WAF) as previously described [15]. The intra- and inter-observer reliability of the grading of chest and elbow radiographs was assessed by calculating $P_{0}$ (observed proportion of agreement) and kappa (statistic for agreement beyond chance expectation) [16].

$$
\text { kappa } \mathrm{K}=\frac{P_{0}-P_{\mathrm{e}}}{1-P_{\mathrm{e}}}
$$

where $P_{\mathrm{c}}$ is the expected proportion of agreement and $P_{o}$ the observed proportion of agreement.

Statistical calculations were based on the chi-square test for dichotomous variables and on the Student's $t$-test for continuous variables. The level of statistical significance was set at $P=0.05$ with two-sided analysis. Calculations of $95 \%$ confidence intervals $(95 \% \mathrm{CI})$ for proportions and odds ratio (OR) and the study power were carried out according to standard procedures $[17,18]$.

The study was approved by the Ethical Committee of the University of Berne.

\section{RESULTS \\ Probands studied, demographic data}

Of the 284 probands, 85 had a complete radiological examination of both elbows. Their agreement to the elbow X-rays was independent of thoracospinal hyperostosis $(31 \%$ in cases with thoracospinal hyperostosis versus $29 \%$ in controls, $\chi^{2}=0.12$, NS, $n=284$ ), as shown previously for the shoulder X-rays [15] as well.
The probands' acceptance of having elbow X-rays done was also independent of a history of extraskeletal pain (32\% with extraskeletal pain versus $28 \%$ without, $\chi^{2}=0.35$, NS, $\left.n=284\right)$ and skeletal pain other than elbow pain (32\% with skeletal pain versus $22 \%$ without, $\chi^{2}=2.64$, NS, $n=284$ ). However, probands with a history of elbow pain were more likely to allow elbow $\mathrm{X}$-rays $(47 \%$ with elbow pain versus $27 \%$ without, $\left.\chi^{2}=7.14, P<0.01, n=284\right)$. This introduced a selection bias with overestimation of the prevalence of a history of elbow pain in the group with full radiological assessment.

Out of the 284 probands, 21 (7 with and 14 without thoracospinal hyperostosis) had to be excluded because of a history of major elbow trauma ( 6 with and 12 without thoracospinal hyperostosis), inflammatory arthritis (1 with and 1 without) or newly detected malignant lymphoma with bone infiltration (1 without). Demographic data of the remaining 263 probands (99 with and 164 without thoracospinal hyperostosis) revealed a slightly higher mean age and male proportion in cases with thoracospinal hyperostosis compared to controls $(71 \pm 9$ years versus $68 \pm 10$ years, $t=2.32$, $P<0.02$ and $77 \%$ versus $65 \%$ males, $\chi^{2}=3.87$, $P<0.05$, respectively). However, there was no difference in the prevalence of a history of heavy work in the past $\left(63 \%\right.$ versus $\left.62 \%, \chi^{2}=0.03, \mathrm{NS}\right)$ or extraskeletal pain $\left(46 \%\right.$ versus $41 \%, \chi^{2}=0.63$, NS) most commonly due to referred pain in cardiovascular disorders. In none of the probands was elbow pain the cause of the actual hospital admission.

For the analysis of clinical complaints, out of the 85 probands with complete radiological elbow documentation, 13 (9 with and 4 without elbow hyperostosis) had to be excluded because of a history of major elbow trauma (8 with and 2 without elbow hyperostosis, respectively), inflammatory arthritis (1 with and 1 without) or osteoarthritis (1 without). Demographic data of the remaining 72 probands are shown in Table I.

Intra-and inter-observer reliability of thoracospinal and elbow hyperostosis assessment

The intra- and inter-observer reliability was excellent for the thoracospinal assessment $\left(P_{0} 0.90-0.95\right.$, kappa $0.80-0.90, n=55-60)$, revealing no major differences between three rheumatologists (PS, NJG, HF) and the radiologist (WAF) [19]. The intra-observer reliability was also excellent for the elbow grading by one of the rheumatologists (NJG) and the radiologist (WAF), (both $P_{0} 0.94$, kappa 0.88, $n=17-18$ ). However, inter-observer reliability was only fair among three rheumatologists (NJG, HF, FH) $\left(P_{0} 0.75-\right.$ 0.83 , kappa $0.50-0.66, n=24$ ) and poor between a rheumatologist (NJG) and the radiologist (WAF) $\left(P_{0}=0.57\right.$, kappa $\left.0.14, n=82\right)$. In general, films were graded higher by the rheumatologists than the radiologist.

Association of elbow and thoracospinal hyperostosis and shoulder hyperostosis respectively

The prevalence of elbow hyperostosis was signifi- 
TABLE I

Synopsis of Clinical Characteristics: 72 Probands With or Without Elbow Hyperostosis

\begin{tabular}{lccccc}
\hline & \multicolumn{4}{c}{ Elbow hyperostosis } \\
\cline { 2 - 6 } & $\begin{array}{c}\text { Present (cases) } \\
(n=48)\end{array}$ & \multicolumn{2}{c}{$\begin{array}{c}\text { Absent (controls) } \\
(n=24)\end{array}$} \\
\hline Age[years](mean \pm SD) & 67 & \pm 8 & 66 & \pm 11 & NS \\
Males & 39 & $(81 \%)$ & 14 & $(58 \%)$ & $P<0.05$ \\
History of heavy work & 26 & $(54 \%)$ & 12 & $(50 \%)$ & NS \\
Extraskeletal pain & 21 & $(44 \%)$ & 12 & $(50 \%)$ & NS \\
\hline
\end{tabular}

cantly higher in cases with thoracospinal hyperostosis as well as in cases with shoulder hyperostosis compared to controls (Tables II and III). All except two cases with elbow hyperostosis showed bilateral hyperostotic features. In addition, seemingly amorphous soft tissue calcifications were present in 7 of 48 probands with elbow hyperostosis $(15 \%)$ but in none of the 24 controls.

Other risk factors for the development of elbow hyperostosis

Males were more likely to show elbow hyperostosis than females $\left(76 \%\right.$ versus $43 \%, \chi^{2}=7.94, P<0.005$, $n=85$, OR $=4.07$ (95\% CI 1.49-11.17)). However, this was only evident in controls without thoracospinal hyperostosis ( $74 \%$ versus $28 \%, \chi^{2}=10.09, P<0.0005$, $n=52$ ), but not in cases with thoracospinal hyperostosis $\left(79 \%\right.$ versus $100 \%, \chi^{2}=1.31$, NS, $\left.n=33\right)$. Similarly, there was a distinctly increased prevalence of elbow hyperostosis only in controls without shoulder hyperostosis $\left(70 \%\right.$ versus $35 \%, \chi^{2}=5.90, P<0.025$, $n=54$ ), but not in cases with shoulder hyperostosis ( $88 \%$ versus $67 \%, \chi^{2}=0.24, n=30$ ). In contrast, a history of heavy work did not influence the prevalence of elbow hyperostosis $\left(69 \%\right.$ versus $65 \%, \chi^{2}=0.01$, NS, $n=85$ ).

Lacking association of a history of elbow pain with thoracospinal hyperostosis

The prevalence of a history of elbow pain any time in the past not related to a major trauma was not different in cases with thoracospinal hyperostosis compared to controls $\left(11 \%\right.$ versus $14 \%, \chi^{2}=0.47$, NS, $n=263$, $\mathrm{OR}=0.77 \quad(95 \%$ CI $0.36-1.65))$. Differentiating between a history of elbow pain during the last 6 months and prior to the last 6 months, the results were $2 \%$ versus $8 \%, \chi^{2}=4.00, P<0.05$ and $10 \%$ versus $10 \%$ respectively, $\chi^{2}=0.01$, NS.

TABLE II

Elbow Hyperostosis in Thoracospinal Hyperostosis (DISH)

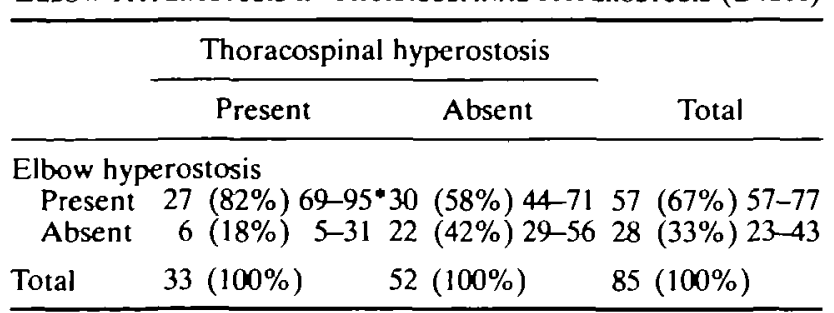

$\chi^{2}=5.32 ; P<0.025$; odds ratio $3.30\left(1.16-9.35^{*}\right)$; $95 \%$ confidence interval.
An analysis for other risk factors for the development of elbow pain was unrevealing. Age, sex, history of heavy work and extraskeletal pain were not associated with an increased prevalence of recalled elbow pain. However, as expected, probands with a complete radiological documentation declared elbow pain slightly more often, most probably due to the selection bias mentioned before.

Doubtful association of a history of elbow pain with elbow hyperostosis

The prevalence of a history of elbow pain any time in the past was not significantly higher in cases with elbow hyperostosis compared to controls (Table IV). Analyzing the data separately for whether the elbow pain occurred in the last 6 months or before the last 6 months, the results were $13 \%$ versus $13 \%, \chi^{2}=0$, NS and $15 \%$ versus $4 \%, \chi^{2}=1.76$, NS. Due to the small number of cases and controls, this study had an estimated chance of only $17 \%$ of detecting a twofold increase in a history of elbow pain any time in the past in cases with elbow hyperostosis compared to controls, or of $27 \%$ for the detection of a threefold increase. However, one could be $70 \%$ sure that a 5.14 -fold increase or more would have been detected with the present study size.

When 20 cases with both elbow and thoracospinal hyperostosis (= elbow DISH) were compared with 18 controls without elbow and without thoracospinal hyperostosis (= controls) the prevalence of a history of elbow pain any time in the past was similar again $(15 \%$ versus $17 \%, \chi^{2}=0.02, n=38, \mathrm{OR}=0.88(95 \% \mathrm{CI}$ $0.15-5.05))$.

\section{DISCUSSION}

In this first controlled study we found the prevalence of hyperostosis was increased about one and a half times in cases with thoracospinal hyperostosis compared to controls without thoracospinal hyperostosis. In addition, we found the prevalence of elbow hyperostosis was increased about one and a half times again in cases with shoulder hyperostosis compared to controls without shoulder hyperostosis. These results underline the multifocal nature of this hyperostotic condition and emphasize the term 'diffuse idiopathic skeletal hyperostosis (DISH)' [1-3].

Four out of five cases with thoracospinal hyperostosis also had elbow hyperostosis emphasizing the frequent occurrence of extraspinal manifestations of

TABLE III

Elbow Hyperostosis in Shoulder Hyperostosis

\begin{tabular}{|c|c|c|c|}
\hline & \multicolumn{2}{|c|}{ Shoulder hyperostosis } & \multirow[b]{2}{*}{ Total } \\
\hline & Present & Absent & \\
\hline \multicolumn{4}{|c|}{ Elbow hyperostosis } \\
\hline $\begin{array}{l}\text { Present } \\
\text { Absent }\end{array}$ & 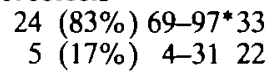 & $\begin{array}{l}(60 \%) 56-64 \\
(40 \%) 36-44\end{array}$ & $\begin{array}{l}57(68 \%) 58-78 \\
27(32 \%) 22-42\end{array}$ \\
\hline Total & $29(100 \%)$ & $(100 \%)$ & $84(100 \%)$ \\
\hline
\end{tabular}

$\chi^{2}=4.51 ; P<0.05$; odds ratio $3.20\left(1.06-9.66^{*}\right)$; ${ }^{*} 95 \%$ confidence interval. 
TABLE IV

Prevalence of a History of Elbow Pain in the Past in Cases with Elbow Hyperostosis Compared to Controis

\begin{tabular}{|c|c|c|c|}
\hline & \multicolumn{2}{|c|}{ Elbow hyperostosis } & \multirow[b]{2}{*}{ Total } \\
\hline & Present & Absent & \\
\hline $\begin{array}{l}\text { History o } \\
\text { Present } \\
\text { Absent }\end{array}$ & $\begin{array}{l}\text { of elbow pain in the } \\
\text { t } 10(21 \%) 9-32^{*} 3 \\
\text { t } 38(79 \%) 68-91\end{array}$ & 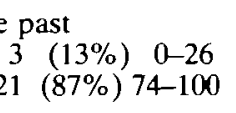 & $\begin{array}{llr}13 & (18 \%) & 9-27 \\
59 & (82 \%) & 73-91\end{array}$ \\
\hline Total & $48(100 \%)$ & $24(100 \%)$ & $72(100 \%)$ \\
\hline
\end{tabular}

DISH. This proportion is in agreement with another study of comparable size [12] but considerably higher than several others $[1,3,11,13]$. However, those reported percentages ranging from $29 \%$ to $60 \%$ were based on 5-21 cases only. On the other hand we cannot exclude a slight overestimation of the prevalence of elbow hyperostosis in our study because of a selection bias; probands with elbow pain in the past had accepted elbow X-rays more often than asymptomatic ones.

More than half the controls without thoracospinal hyperostosis still showed elbow hyperostosis, which is considerably higher than reported previously in two smaller series $[1,11]$. This high prevalence of peripheral hyperostosis in the absence of spinal involvement may be due to several possible causes. Extraspinal manifestations of DISH may precede spinal changes or even involve the extraspinal skeleton without the spine [1]. In addition, enthesopathies with ligamentous or capsular ossification are not specific for DISH but can occur in several different disorders such as ankylosing spondylitis and related spondylarthropathies [20], acromegaly, hypertrophic osteoarthropathy, hypervitaminosis A, fluorosis, calcium pyrophosphate deposition disease [1]. Furthermore, it remains an open question, to what extent local factors are responsible for the development of local hyperostotic changes. Interestingly, elbow hyperostosis seems to be distinctly more prevalent than shoulder hyperostosis and to exhibit a less pronounced increase in cases with thoracospinal hyperostosis compared to controls. Mechanical factors including repetitive strain could also play a role. However, in accordance with previous observations $[9,12]$ we found elbow hyperostosis to be usually bilateral and not just on the dominant side. Moreover, elbow hyperostosis was as prevalent in probands with a history of heavy work as in those without. These findings cast doubt on the importance of general mechanical factors for the pathogenesis of peripheral hyperostotic features. Finally, there are many open questions about the relevance of different systemic factors such as genetic, metabolic-endocrine and toxic. Interestingly, males were more likely to exhibit elbow hyperostosis than females if they had no hyperostotic features at the spine or the shoulder.

The criteria introduced for radiological grading of elbow hyperostosis revealed an excellent intra-observer reliability but only a moderate inter-observer reliability. This points out how important it is to have $\mathrm{X}$-rays assessed by the same person throughout the whole study period and how difficult it can become to compare results from different groups, even if common, standardized criteria are used.

Our results confirm elbow pain as a common complaint [21-23]. One out of five cases with elbow hyperostosis recalled elbow pain at some time in the past. This proportion is comparable to the results of most uncontrolled studies $[1-3,10,14]$. Interestingly, elbow pain was a distinctly less common complaint than shoulder pain $[1,14]$. In particular, identical probands gave a history of shoulder pain twice as often as elbow pain [15]. Whether this difference is due to the restricted movement at the elbow joint or due to a restricted retrocoracoidal or subacromial space in the shoulder joint on maximum internal or external rotation or abduction, leading to tendon impingement, remains open.

A history of elbow pain any time in the past was one and a half times more prevalent in cases with elbow hyperostosis than in controls; but this difference did not reach statistical significance. This could be due to the small number of cases and controls. To overcome this, a total of 400 probands would be necessary. However, the observation that four out of five cases with elbow hyperostosis did not remember any elbow pain episode in the past casts doubt on the clinical relevance of these radiological changes. This is in contrast to our findings in shoulder hyperostosis where cases with shoulder hyperostosis, irrespective of the presence of thoracospinal hyperostosis, were twice as likely to develop shoulder pain than controls. In cases with shoulder hyperostosis with thoracospinal hyperostosis they were four times more likely to develop shoulder pain than were controls [15]

As all the probands studied were asymptomatic at the moment of investigation, no physical examination could be performed during the pain episode. However, it would be interesting to include a physical examination with documentation of the range of elbow movements, since similar restriction has been reported elsewhere in DISH [1].

From these results we conclude that elbow hyperostosis is a most common finding in elderly people. It can be a manifestation of diffuse idiopathic skeletal hyperostosis (DISH). Its clinical relevance seems doubtful. Whether further, much larger studies to clarify this question would be worth performing, is doubtful.

\section{ACKNOWLEDGEMENTS}

We thank Dr Esther Hächler for interviewing probands and all colleagues of the Departments of Internal Medicine (Professor P. W. Straub, Professor H. Studer, Professor T. Hess) and Cardiovascular Surgery (Professor U. Althaus), Inselspital Berne for letting us examine their patients. We also thank Mrs J. L. Childs for secretarial help.

\section{REFERENCES}

1. Resnick D, Shapiro RF, Wiesner KB, Niwayama G, 
Utsinger PD, Shaul SR. Diffuse idiopathic skeletal hyperostosis (DISH) [Ankylosing hyperostosis of Forestier and Rotes-Querol]. Semin Arthritis Rheum 1978;7:153-87.

2. Utsinger PD. Diffuse idiopathic skeletal hyperostosis. Clin Rheum Dis 1985;11:325-51.

3. Arlet J, Mazières B. La maladie hyperostosique. Rev Med Interne 1985;6:553-64.

4. Forestier J, Rotes-Querol J. Senile ankylosing hyperostosis of the spine. Ann Rheum Dis 1950;9:321-30.

5. Ott VR. Über die spondylosis hyperostotica. Schweiz Med Wschr 1953;83:790-9.

6. Forestier J, Lagier R. Ankylosing hyperostosis of the spine. Clin Orthop 1971;74:65-83.

7. Resnick D, Niwayama G. Radiographic and pathological features of spinal involvement in diffuse idiopathic skeletal hyperostosis. Radiology 1976; 119:559-68.

8. Harris J, Carter AR, Glick EN, Storey GO. Ankylosing hyperostosis. Clinical and radiological features. Ann Rheum Dis 1974;33:210-15.

9. Resnick D, Staul SR, Robins JM. Diffuse idiopathic skeletal hyperostosis (DISH): Forestier's disease with extraspinal manifestations. Radiology 1975;115:513-24.

10. Utsinger PD, Resnick D, Shapiro R. Diffuse skeletal abnormalities in Forestier's disease. Arch Intern Med 1976;136:763-8.

11. Dirheimer Y, Borges d'Almeida MT, Christmann D, Ramshey A. Aspects spécifiques et non-spécifiques des atteintes radiologiques extra-spinales de l'hyperostose vertebrae. Rhumatologie 1981;33:369-72.

12. Littlejohn GO, Urowitz M. Peripheral enthesopathy in diffuse idiopathic skeletal hyperostosis (DISH): a radiological study. $J$ Rheumatol 1982;9:568-72.

13. Robotti GC, Schneekloth G. Extravertebrale Manifestationen der ankylosierenden Hyperostose ( $M$. Forestier). Radiologe 1982;22:408-11.
14. El Garf A, Khater R. Diffuse idiopathic skeletal hyperostosis (DISH), a clinicoradiological study of the disease pattern in middle eastern populations. $J$ Rheumatol 1984;11:804-7.

15. Beyeler $\mathrm{Ch}$, Schlapbach $\mathrm{P}, \mathrm{Gerber} \mathrm{NJ}$, et al. Diffuse idiopathic skeletal hyperostosis (DISH): a cause of shoulder pain? A controlled study. BrJ Rheumatol 1990;29:349-53.

16. Kelsey JL, Thompson WD, Evans AS. Methods in observational epidemiology. Monographs in epidemiology and biostatistics. Vol. 10. Oxford: Oxford University Press, 1986: 288-93.

17. Gardner MJ, Altman DG. Statistics with confidence. London: British Medical Journal, 1989;28-33; $50-63$.

18. Schlesselman JJ. Case-control studies. Oxford: Oxford University Press, 1982:144-70.

19. Schlapbach P, Beyeler Ch, Gerber NJ, et al. Diffuse idiopathic skeletal hyperostosis (DISH): a cause of back pain? A controlled study. Br J Rheumatol 1989;28:299-303.

20. Paolaggi JB, Coutet MC, Strutz Ph, Siaud JR, le Parc JM, Auguier L. Les enthesopathies des spondylarthropathies inflammatoires. Rev Rheum Mal Osteoartic 1984;51:457-62.

21. Hadler NM. The role of work and of working in disorders of the upper extremity. Bailliere's Clin Rheumatol 1989;3.1:121-41.

22. Cunningham LS, Kelsey JL. Epidemiology of musculoskeletal impairments and associated disability. Am J Public Health 1984;74:574-9.

23. Valkenburg H. Jaarverslag Instituut Epidemiologie en Zesde Voortgangsverlag van het, Epidemiologisch Preventief Onderzoek Zoetermeer (EPOZ). University of Maastrich, The Netherlands, 1980.
1992

July

July

October

September $10-11$

November $\quad 9-13$

1993

May
13-14 Advanced Course in Rheumatology. GLASGOW (Prof. R. Sturrock).

\section{ANNOUNCEMENTS AND CALENDAR FOR 1992-1993}

BSR Rehabilitation Course. LEEDS (Prof. M. A. Chamberlain).

7th EULAR Symposium and BSR Annual General Meeting. BARBICAN, LONDON.

Core Course in Rheumatology. LONDON (Dr D. Isenberg).

Paediatric Course. BIRMINGHAM (Dr T. Southwood).

Senior Registrar Travelling Fellowship. BIRMINGHAM (Prof. P. Bacon).$$
13
$$ 